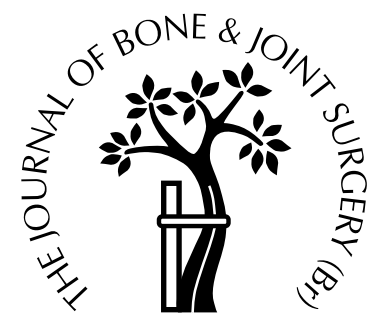

\title{
Resection arthroplasty of the sternoclavicular joint for the treatment of primary degenerative sternoclavicular arthritis
}

\author{
Andreas Pingsmann, Theodore Patsalis, Ivo Michiels \\ From Essen University Medical School, Essen, Germany
}

$\mathbf{W}$ e describe the mid-term clinical results of the surgical treatment of primary degenerative arthritis of the sternoclavicular joint in eight women. They had not responded to conservative treatment and underwent a limited resection arthroplasty. For preand postoperative clinical evaluation we used the Rockwood score for the sternoclavicular joint. Postoperatively, the Constant score was also determined. The mean follow-up was 31 months (10 to 82).

The median Rockwood score increased from 6 to 12.5 points. The median postoperative Constant score was 87 (65 to 91). Four patients had an excellent, three a good, and one a poor result. All patients were pleased with the cosmetic result.

Resection arthroplasty is an effective and safe treatment for chronic, symptomatic degenerative arthritis of the sternoclavicular joint with a high degree of patient satisfaction.

J Bone Joint Surg [Br] 2002;84-B:513-7. Received 6 July 2001; Accepted after revision 2 November 2001

Primary degenerative arthritis of the sternoclavicular (SC) joint is most commonly seen in postmenopausal women. With increasing age, asymmetry and local bony prominence are common clinical findings. ${ }^{1-4}$ Postmortem studies have shown degenerative changes in the SC joint in all patients after the fifth decade. ${ }^{5,6}$ Silberberg et al ${ }^{6}$ distinguished between changes due to ageing and those arising from degenerative arthritis. In symptomatic patients pain is usually related to activity, but may be present at rest. The pain is felt in the clavicular region and often radiates to the shoulder. If untreated, the acute local pain and swelling usually settle after one or two months, and other symptoms resolve gradually over nine to 12 months. ${ }^{7}$ Conservative

A. Pingsmann, MD, Orthopaedic Surgeon

T. Patsalis, MD, Orthopaedic Surgeon

I. Michiels, PhD, Orthopaedic Surgeon

Department of Orthopaedics, Essen University Medical School, Hufelandstrasse 55, 45122 Essen, Germany.

Correspondence should be sent to Dr A. Pingsmann.

(C)2002 British Editorial Society of Bone and Joint Surgery 0301-620X/02/412601\$2.00 treatment with non-steroidal anti-inflammatory drugs may be sufficient. ${ }^{8-10}$ Westermann $^{11}$ and Kowallik, ${ }^{8}$ however, diagnosed degenerative SC arthritis, clinically and radiologically, equally in men and women from the third decade onwards. They found a preponderance in housewives and manual labourers. Westermann ${ }^{11}$ excised the medial aspect of the clavicle with excellent results in a 60-year-old man and a 50-year-old woman. Disappointed with the outcome after conservative treatment, he subsequently operated on an unreported number of patients obtaining equally good results. Although primary arthritis of the SC joint is common, the place of surgical treatment is not well documented. ${ }^{7,12}$ We therefore present our mid-term results of resection arthroplasty of the $\mathrm{SC}$ joint.

\section{Patients and Methods}

We treated eight women with primary degenerative arthritis of the SC joint by resection arthroplasty. The mean age at surgery was 54 years (47 to 61) and the mean follow-up was 31 months (10 to 82 ). Clinical evaluation was carried out before and after operation using the scoring system described by Rockwood et $\mathrm{al}^{13}$ (Table I). This is a selfassessment score with four grades available each for pain, range of motion, strength, limitation and subjective result. The overall result is considered excellent for scores of 13 to 15 , good for scores of 10 to 12, fair for scores of 7 to 9 and poor for scores of less than 7. The score of Constant and Murley ${ }^{14}$ was also determined at the most recent follow-up examination.

In all patients no contributing factors could be elicited with the exception of one who reported a fall on to the affected side three months before the onset of symptoms. In all patients the side of the dominant arm was affected. All except one reported pain at rest occasionally disturbing sleep. This was localised in the upper chest radiating to the shoulder, the ipsilateral side of the neck and occasionally to the ipsilateral arm. It was aggravated by overhead activities. The mean duration of symptoms before surgery was 20 months (3 to 36). The symptoms did not respond to conservative treatment in the form of non-steroidal antiinflammatory agents, local cryotherapy, and physiotherapy. Two patients were also treated with WHO stage-II opioids and four had local injections of steroid and local anaes- 
Table I. The scoring system of Rockwood et $\mathrm{al}^{13}$ for clinical evaluation of degenerative arthritis of the SC joint, and the preoperative and postoperative scores for the eight women treated by resection arthroplasty.

\begin{tabular}{|c|c|c|c|c|c|c|c|c|c|c|c|c|c|c|c|c|c|}
\hline \multirow[b]{3}{*}{ Category } & \multirow[b]{3}{*}{ Points } & \multicolumn{16}{|c|}{ Case number } \\
\hline & & \multicolumn{2}{|c|}{1} & \multicolumn{2}{|l|}{2} & \multicolumn{2}{|l|}{3} & \multicolumn{2}{|l|}{4} & \multicolumn{2}{|l|}{5} & \multicolumn{2}{|l|}{6} & \multicolumn{2}{|l|}{7} & \multicolumn{2}{|l|}{8} \\
\hline & & Preop & Postop & Preop & Postop & Preop & Postop & Preop & Postop & Preop & Postop & Preop & Postop & Preop & Postop & Preop & Postop \\
\hline \multicolumn{18}{|l|}{ Pain } \\
\hline None & 3 & & 3 & & 3 & & & & & & & & 3 & & 3 & & 3 \\
\hline Slight & 2 & & & 2 & & & & & 2 & & & & & & & & \\
\hline Moderate & 1 & 1 & & & & 1 & 1 & & & & & & & 1 & & 1 & \\
\hline Severe (at rest) & 0 & & & & & & & 0 & & 0 & 0 & 0 & & & & & \\
\hline \multicolumn{18}{|l|}{ Range of motion } \\
\hline Normal & 3 & & & & 3 & & 3 & 3 & 3 & 3 & 3 & 3 & & 3 & 3 & 3 & 3 \\
\hline $\begin{array}{l}\text { Slight restriction } \\
(<25 \%)\end{array}$ & 2 & 2 & 2 & 2 & & 2 & & & & & & & 2 & & & & \\
\hline $\begin{array}{l}\text { Moderate restriction } \\
(25 \% \text { to } 50 \%)\end{array}$ & 1 & & & & & & & & & & & & & & & & \\
\hline $\begin{array}{l}\text { Severe restriction } \\
(>50 \%)\end{array}$ & 0 & & & & & & & & & & & & & & & & \\
\hline \multicolumn{18}{|l|}{ Strength } \\
\hline Normal & 3 & & 3 & & 3 & & 3 & & & & & 3 & & 3 & 3 & 3 & 3 \\
\hline $\begin{array}{l}\text { Slight weakness } \\
(<25 \%)\end{array}$ & 2 & & & & & 2 & & 2 & 2 & & 2 & & 2 & & & & \\
\hline $\begin{array}{l}\text { Moderate weakness } \\
(25 \% \text { to } 50 \%)\end{array}$ & 1 & 1 & & 1 & & & & & & 1 & & & & & & & \\
\hline $\begin{array}{l}\text { Severe weakness } \\
(>50 \%)\end{array}$ & 0 & & & & & & & & & & & & & & & & \\
\hline \multicolumn{18}{|l|}{ Limitation } \\
\hline None & 3 & & 3 & & 3 & & & & & & & & & & 3 & & 3 \\
\hline Slight & 2 & & & & & & 2 & & 2 & & & & 2 & 2 & & 2 & \\
\hline Moderate & 1 & 1 & & 1 & & 1 & & & & & 1 & 1 & & & & & \\
\hline Severe & 0 & & & & & & & 0 & & 0 & & & & & & & \\
\hline \multicolumn{18}{|l|}{ Subjective result } \\
\hline Excellent & 3 & & 3 & & 3 & & & & & & & & & & & & 3 \\
\hline Good & 2 & & & & & & & & 2 & & & & 2 & & 2 & & \\
\hline Fair & 1 & & & & & & 1 & & & & & & & & & & \\
\hline Poor & 0 & 0 & & 0 & & 0 & & 0 & & 0 & 0 & 0 & & 0 & & 0 & \\
\hline Total score (points) & 15 & 5 & 14 & 6 & 15 & 6 & 10 & 5 & 11 & 4 & 6 & 7 & 11 & 9 & 14 & 9 & 15 \\
\hline
\end{tabular}

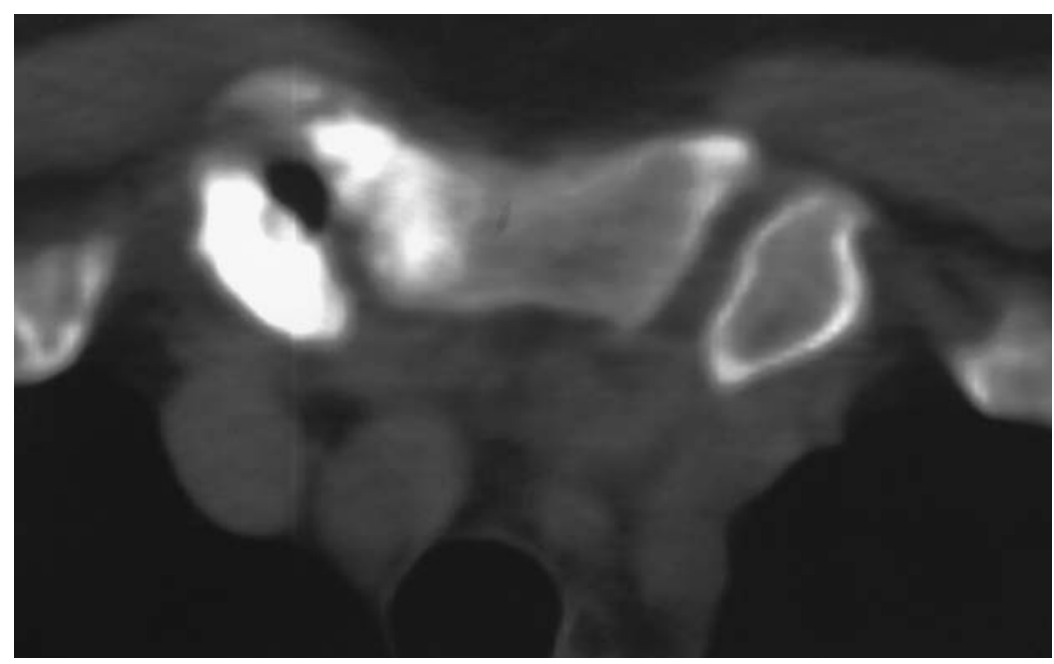

Fig. 1

Case 2. Preoperative CT shows an asymmetrical loss in height of the joint space and a vacuum phenomenon in the right $\mathrm{SC}$ joint.

thetic. Acupuncture had been used in one patient who also received low-potency opioids.

Clinical examination showed localised tenderness and swelling of the SC joint. The push-down test which consists of applying downward force on the medial clavicle, the cross-shoulder sign, and resisted arm abduction were the most reliable clinical methods of reproducing the symptoms. Some patients had limited movement of the neck. Radiography and CT (Fig.1) confirmed hypertrophic arthritis in six patients. A ganglion was present in one patient. In two patients a bone scan showed localised uptake in the region of the $\mathrm{SC}$ joint. 


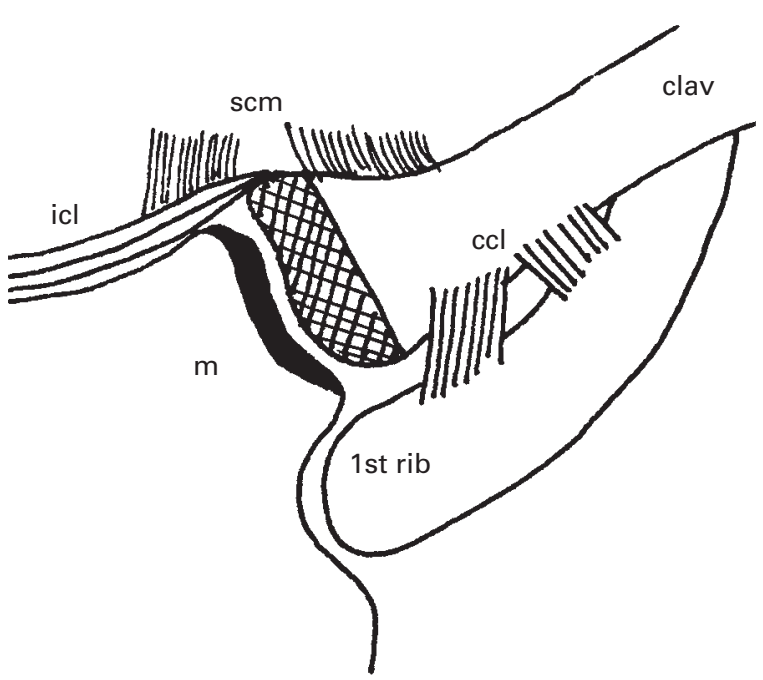

Fig. 2

Diagram showing the surgical site of the SC joint. The crosshatched area indicates the bone to be excised (clav, clavicle; ccl, costoclavicular ligament; icl, interclavicular ligaments; m, manubrium sterni; scm, insertions of the sternocleidomastoid muscle).

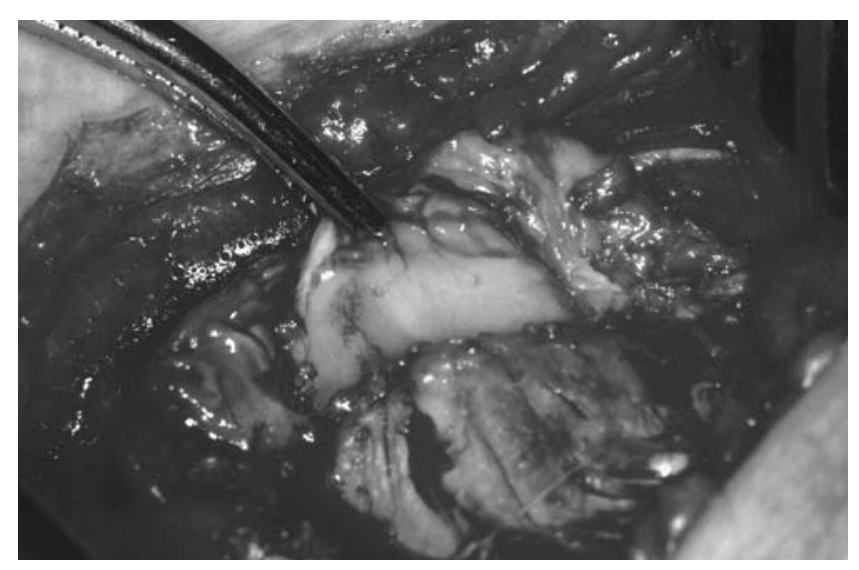

Fig. 3a

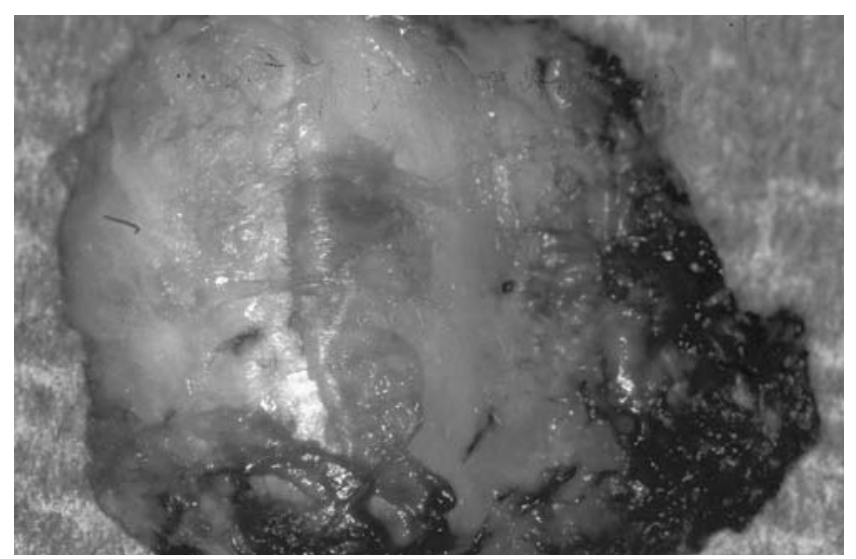

Intraoperative findings. Figure $3 \mathrm{a}$ - The clamp is attached to the articular disc. Figure $3 \mathrm{~b}-$ The articular disc and a slice of approximately $1 \mathrm{~cm}$ have been removed from the medial clavicle. Figure $3 \mathrm{c}$ - The excised slice of the medial clavicle demonstrates loss of the surface of the cartilage and small inferior bony prominences.
Surgery was carried out under general anaesthesia in a semi-sitting position. The joint capsule was incised through a small incision along the medial aspect of the clavicle (Fig. 2). The articular disc was removed and the articular surface with 8 to $10 \mathrm{~mm}$ of the medial clavicle were excised, preserving the attachments of the interclavicular, sternoclavicular and costoclavicular ligaments (Figs $3 \mathrm{a}$ and $3 \mathrm{~b})$. As the intraoperative findings within the joint varied considerably, the direction of the osteotomy and the amount of bone removed also varied. The joint gap after excision measured about $1 \mathrm{~cm}$ in all patients. The stability of the joint was assessed by moving the arm and observing that there was no subluxation of the remaining clavicle. Degenerative changes of the disc were confirmed macroscopically in all patients. The medial clavicle was hypercartilage had an ivory appearance (Fig. 3c). The capsule was carefully closed, and much soft tissue was placed in the gap. Postoperatively, the arm was immobilised for two days. Assisted active shoulder exercises started on the third day. Lifting and carrying were allowed after six weeks.

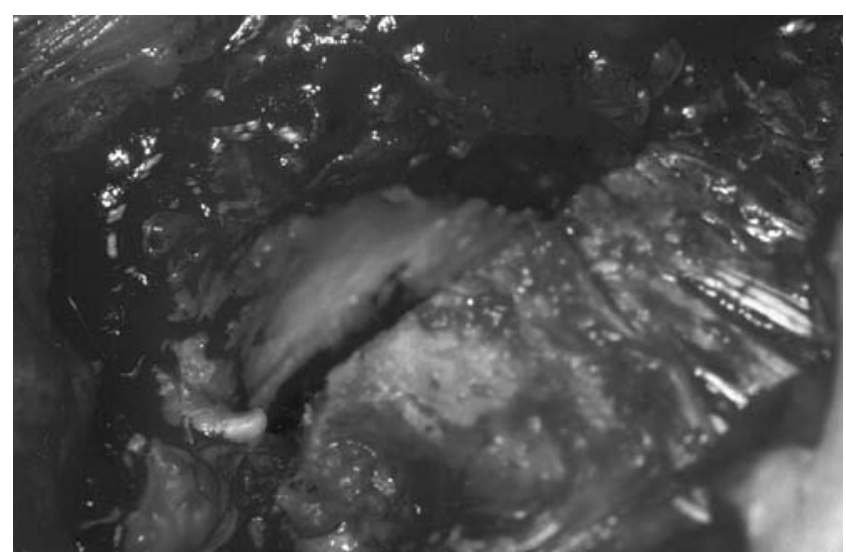

Fig. 3b trophied, but there were no osteophytes. The articular

Fig. 3c 
Table II. The scoring system of Constant and Murley ${ }^{14}$ for evaluation of outcome at the most recent follow-up after resection arthroplasty for degenerative arthritis of the SC joint in eight women

\begin{tabular}{lcrrrrrrrr}
\hline & \multicolumn{1}{c}{ Case number } & & & & \\
\cline { 2 - 10 } Category & Points & $\mathbf{1}$ & $\mathbf{2}$ & $\mathbf{3}$ & $\mathbf{4}$ & $\mathbf{5}$ & $\mathbf{6}$ & $\mathbf{7}$ & $\mathbf{8}$ \\
\hline Pain & 15 & 15 & 15 & 5 & 10 & 5 & 15 & 15 & 15 \\
Activities of daily living & & & & & & & & & \\
$\quad$ Activity level & 10 & 10 & 10 & 0 & 10 & 0 & 6 & 10 & 10 \\
$\quad$ Positioning & 10 & 10 & 10 & 10 & 10 & 10 & 10 & 10 & 10 \\
Abduction/lateral elevation & 10 & 10 & 8 & 8 & 10 & 10 & 10 & 10 & 10 \\
Flexion/forward elevation & 10 & 10 & 10 & 10 & 10 & 10 & 10 & 10 & 10 \\
Rotation & & & & & & & & & \\
$\quad$ External & 10 & 10 & 10 & 10 & 10 & 10 & 10 & 8 & 10 \\
$\quad$ Internal & 10 & 8 & 8 & 8 & 10 & 10 & 10 & 8 & 10 \\
Power & 25 & 14 & 20 & 16 & 12 & 10 & 16 & 15 & 14 \\
Total score & 100 & 87 & 91 & 67 & 82 & 65 & 87 & 86 & 89 \\
\hline
\end{tabular}

\section{Results}

All patients regained either their preoperative or a full range of movement one week after surgery. There were no complications of surgery. All patients except one reported significant improvement in the pain, movement and strength of the arm, and their ability to work, and considered the outcome a success. The Rockwood score increased from a median of six points preoperatively to 12.5 points postoperatively (Table I). The clinical result was rated excellent in four patients (13 to 15 points), good in three patients (10 to 12 points) and poor in one $(<7$ points). The median postoperative Constant score was 87 (65 to 91) out of 100 points (Table II). All patients were pleased with the cosmetic result. No patient developed instability or signs of inflammation at the site of the excised joint.

Histological examination of six joints showed perifocal cartilaginous hyperplasia, cartilage clefts, moderate formation of lamellar bone at the medial aspect of the clavicle and moderate degenerative changes with focal stromal siderosis of the articular disc.

\section{Discussion}

Descriptions of the surgical treatment for pathology of the SC joint mainly consider post-traumatic conditions. ${ }^{13,15,16}$ There are few reports of the outcome after surgery for degenerative arthritis. ${ }^{7,17-19}$ Bonnin $^{20}$ described six cases of spontaneous subluxation of the SC joint in a series of 11 patients. These patients were asymptomatic and treatment was therefore not discussed. In one joint, a biopsy showed marked degenerative changes. He speculated that an agerelated increase in tissue tension caused the subluxation. Pierce ${ }^{18}$ described the surgical exploration of four patients with pain in the SC joint after trauma. In one 28 -year-old patient the joint was enlarged and showed degenerative changes; no abnormal pathology was found in the other three. He described considerable symptomatic improvement four months after excising the articular disc. Rockwood et $\mathrm{al}^{13}$ described 15 patients who had surgical treatment for pain in the SC joint secondary to trauma or unsuccessful previous surgery. The patients were predominantly male and younger (mean age 33 years) than the eight women in our study. None of our patients had symptoms of instability such as a grinding or springing sensations in the joint. The stability of the SC joint depends mainly on the costoclavicular ligament and to a less extent on the conformity of the joint and the articular disc. ${ }^{3,16,21}$ The ligamentous structures of the SC joint were preserved in our patients.

Kofoed, Thomsén and Lindenberg, ${ }^{22}$ and Searle et $\mathrm{al}^{21}$ emphasised the need for a thorough clinical assessment and incisional biopsy in patients with degenerative changes in the SC joint, especially in those with a history of or concomitant oropharyngeal malignancy. Swelling of the SC joint has been reported after dissection of the neck and attributed to muscle weakness caused by surgical denervation and radiotherapy. ${ }^{23,24}$ Sclerosis of the medial end of the clavicle may be associated with primary or secondary inflammatory joint disease or overload of the small inferior articular facet. ${ }^{12,25,26}$ It has been reported to produce symptoms in premenopausal women. ${ }^{9,25}$ Arlet and Ficat ${ }^{9}$ described 12 women with the spontaneous onset of symptoms arising from the SC joint. Patients between 49 and 66 years of age were successfully treated conservatively, although two aged 30 and 33 years required resection arthroplasty. Both had a good result 18 months after surgery. Only Bremner ${ }^{7}$ has described the long-term results of $\mathrm{SC}$ resection arthroplasty. He followed up 12 middle-aged women aged between 34 and 63 years for ten years. Seven underwent surgical treatment. At surgery, there was complete or partial destruction of the articular disc and villous synovitis. Vascularised pannus was seen to cover the articular surfaces, although degenerative or rheumatoid arthritis could not be confirmed. He carried out a synovectomy and excision of the medial $2.5 \mathrm{~cm}$ of the clavicle with good results. Kowallik ${ }^{8}$ classified two types of degenerative arthritis of the SC joint. One imitated a tumour of the sternal end of the clavicle, but produced no or only very few symptoms. The second was characterised by minimal enlargement of the joint, but was extremely painful. The symptoms were most severe for a period of one to six months and subsided almost completely after three to four years.

Unlike Bremner, ${ }^{7}$ we found localised synovitis in only two joints, and no osteolysis of the medial aspect of the clavicle. Histological examination which was carried out in six of our eight patients confirmed advanced degenerative arthritis. Excision arthroplasty is a safe and effective treatment for those patients who fail to respond to conservative treatment. Minimal resection and preservation of the stabilising joint structures allow early rehabilitation and provide good clinical and cosmetic results. 
No benefits in any form have been received or will be received from a commercial party related directly or indirectly to the subject of this article.

\section{References}

1. Fick R. Handbuch der Anatomie. Jena: Fischer; 1911.

2. Rathcke L. Beitrag zur normalen und pathologischen Anatomie des Sternoclaviculargelenkes. Deutsche Ztschr Chir 1937;249:162-9.

3. DePalma AF. Surgical anatomy of acromioclavicular and sternoclavicular joints. Surg Clin North Am 1963;43:1541-50.

4. Kalliomäki JL, Viitanen S-M, Virtama P. Radiological findings of sternoclavicular joints in rheumatoid arthritis. Acta Rheumatol Scand 1968;14:233-40.

5. Langen P. Untersuchungen über die Altersveränderungen und Abnutzungserscheinungen am Sternoclaviculargelenk. Virchows Arch Pathol Anat 1934;293:381-408.

6. Silberberg M, Frank EL, Jarrett SR, Silberberg R. Aging and osteoarthritis of the human sternoclavicular joint. Am J Pathol 1959;35:851-65.

7. Bremner RA. Monarticular, non-infective subacute arthritis of the sterno-clavicular joint. J Bone Joint Surg [Br] 1959;41-B:749-53.

8. Kowallik B. die Arthrosis deformans des Brustbein-Schlüsselbeingelenkes. Zblchir 1951;10:672-5.

9. Arlet J, Ficat P. Osteoarthritis of the sterno-clavicular joint. Ann Rheum Dis 1958;17:97-100.

10. Hamilton-Wood C, Hollingworth P, Dieppe P, Ackroyd C, Watt I. The painful swollen sterno-clavicular joint. $\mathrm{Br} \quad J \quad$ Radiol 1985;58:941-5.

11. Westermann HH. Die Erkrankungen der Sternoklavikulargelenke mit besonderer Berücksichtigung der Arthrosis deformans. Arch Klin Chir 1942;203:19-42.

12. Brower AC, Sweet DE, Keats TE. Condensing osteitis of the clavicle: a new entity. Am J Roentgenol 1974;121:17-21.
13. Rockwood CA Jr, Groh Gl, Wirth MA, Grassi FA. Resection arthroplasty of the sternoclavicular joint. J Bone Joint Surg [Am] 1997;79-A:387-93

14. Constant CR, Murley AHG. A clinical method of functional assessment of the shoulder. Clin Orthop 1987;214:160-4.

15. Waskowitz WJ. Disruption of the sternoclavicular joint: an analysis and review. Am J Orthop 1961:3:176-9.

16. Rockwood CA Jr, Wirth MA. Disorders of the sternoclavicular joint. In: Rockwood CA Jr, Matsen FA III, eds. The Shoulder. Vol.1. 2nd ed. Philadelphia: W. B. Saunders; 1998:555-609.

17. Abbott LC, Lucas DB. The function of the clavicle. Its surgical significance. Ann Surg 1954;140:583-99.

18. Pierce RO Jr. Internal derangement of the sternoclavicular joint. Clin Orthop 1979;141:247-50.

19. Turowski B, Dresing K, Sievers KW. Swelling of the sternoclavicular joint. Unfallchirurg 1995;98:427-31.

20. Bonnin JG. Spontaneous subluxation of the sternoclavicular joint. $\mathrm{Br}$ Med J 1960 (II):274-5.

21. Searle AE, Gluckman P, Sanders R, Breach NM. Sternoclavicular joint swellings: diagnosis and management. $\mathrm{Br} J$ Plast Surg 1991;44:403-5.

22. Kofoed H, Thomsen $\mathbf{P}$, Lindenberg $\mathbf{S}$. Serous synovitis of the sternoclavicular joint. Scan J Rheumatol 1985;14:61-4.

23. Gorman JB, Stone RT, Keats TE. Changes in the sternoclavicular joint following radical neck dissection. Am J Roentgenol Radium Ther Nucl Med 1971;111:584-7.

24. Cantlon GE, Gluckman JL. Sternoclavicular joint hypertrophy following radical neck dissection. Head Neck Surg 1983;5:218-21.

25. Cone RO, Resnik D, Goergen TG et al. Condensing osteitis of the clavicle. Am J Roentgenol 1983;141:387-8.

26. Vierboom, MA, Steinberg JD, Mooyaart EL, van Rijswijk MH. Condensing osteitis of the clavicle: magnetic resonance imaging as an adjunct method for differential diagnosis. Ann Rheum Dis 1992;51:539-41. 